\title{
Effect of Edible Coatings Containing Soy Protein Isolate (SPI) on the Browning and Moisture Content of Cut Fruit and Vegetables
}

\author{
Jinhan Shon ${ }^{1}$ and Yong-Hwa $\mathrm{Choi}^{2 *}$ \\ ${ }^{1}$ Department of Food Science and Technology and Functional Food Research Center, Chonnam National University, \\ Gwangju 500-757, Republic of Korea \\ ${ }^{2}$ College of Ecological \& Environmental Science, Kyungpook National University, Sangju 742-711, Republic of Korea
}

Received July 17, 2011; Accepted September 5, 2011

\begin{abstract}
Effectiveness of edible coatings containing soy protein isolate (SPI), in reducing oxidative browning and moisture loss during storage $\left(4^{\circ} \mathrm{C}\right)$ of cut apples, potatoes, carrots, and onions was investigated. The SPI coatings were shown to have antioxidative activity. Furthermore, addition of carboxymethyl cellulose (CMC) to the formulations significantly improved its antioxidative activity. Oxidative discoloration, as determined by Commission Internationale De I'Eclairage (CIE) lightness $\left(L^{*}\right)$, redness $\left(a^{*}\right)$, and yellowness $\left(b^{*}\right)$ color scale, was significantly reduced $(p<0.05)$ by SPI coating treatments over a storage time of $120 \mathrm{~min}$. Loss of lightness was reduced by SPI coatings with and without $\mathrm{CMC}$. These respectively showed 4.03 and $3.71 \%$ change of $L^{*}$ value compared to $8.56 \%$ for control. Browning of the control in cut potatoes was significantly increased by $106.6 \%$ in contrast to 34.3 and $35.2 \%$ for SPI coatings with and without CMC, respectively. The $b^{*}$ values also reflected effectiveness of SPI. Moisture barrier effect was significantly better for the treatments, compared to the control. SPI coatings reduced moisture loss in apples and potatoes, respectively, by 21.3 and $29.6 \%$ over the control. Cut onions did not show any treatment effect both in terms of browning and moisture loss. SPI coatings prove to be good moisture barrier and antioxidative property.
\end{abstract}

Key words: edible film, moisture barrier, oxidative browning, oxygen barrier

\section{Introduction}

Oxidative degradation of many food products is a major problem for food industry. The mechanism of browning is well characterized and is mainly due to the action of the ubiquitous enzyme, polyphenol oxidase (PPO) [Sapers, 1993]. Fresh-cut fruits and vegetables have a shorter shelf-life than their whole counterparts because of increased susceptibility to oxidative deterioration if not controlled. Physical and oxidative damage during storage and transportation, and ripening activates PPO in fruits [Le Tien et al., 2001] and vegetables [Fujita et al., 1991; Le Tien et al., 2001]. Various chemicals including sulfite, citric acid, ascorbic acid derivatives, cinnamate, benzoate, and cyclodextrins are used to reduce browning [Sapers, 1993]. However, health concerns have limited their application. Therefore, extension of the window of freshness of fruits and vegetables by natural means is of great interest to the food industry. Other approaches, including modified atmosphere packaging and vacuum packaging

*Corresponding author

Phone: +82-54-530-1201; Fax: +82-54-530-1209

E-mail: ychoi@knu.ac.kr

http://dx.doi.org/10.3839/jabc.2011.032 can delay browning, excessive reduction of oxygen will damage the product by inducing anaerobic metabolism, leading to breakdown and off-flavor formation.

There is currently considerable interest in edible coatings or films because of their potential to improve the quality and shelf life of foods [McHugh and Senesi, 2000]. In recent years, edible films or coatings included casein, collagen, chitosan, gelatin, soy protein, whey protein, and methyl cellulose-based films [Were et al., 1999; Haque et al., 2009; Shon et al., 2010]. Edible coatings or films are suitable for fresh and minimally processed fruits and vegetables to improve appearance, delay ripening and color changes, and functions as a carrier of antimicrobials and antibrowning agents. Edible coatings or films provide a barrier to moisture and oxygen, and consequently reduce the oxidation reaction rates [Kester and Fennema, 1986]. Edible coatings containing hydrocolloids and proteins, such as milk protein, conceivably reduce oxidative degradation of cut fruits and vegetables via inhibition of PPO [Le Tien et al., 2001; Shon and Haque, 2007a]. In addition, edible coatings based on cellulose gums effectively delayed ripening in some climacteric fruits like mangoes, papayas, and bananas and significantly reduced enzymatic browning on sliced mushrooms [Nisperos-Carriedo et al., 1991]. 
Soy proteins have excellent nutritional and functional properties as well as the ability to form films or coatings [Were et al., 1999] and are widely used as low-cost protein additives in processed meats [Liu et al., 2000]. Soy protein isolate (SPI) was recently found its efficacy as an edible coating to enhance shelflife of cut raw Han-Woo beef [Shon et al., 2010]. Apple, potato, and carrot are known to be susceptible to oxidative browning [Le Tien et al., 2001; Zhang et al., 2005]. On the other hand, browning mechanism of onion is different since it is not susceptible to PPO induced browning due to its intrinsic content of PPO inhibitory factor [Fujii and Hosoda, 2005]. The objective of this study was to evaluate the effect of SPI-based edible coating to reduce browning and moisture content of cut fruit and vegetables during refrigerated storage.

\section{Materials and Methods}

Materials. Soy protein isolate (SPI) was from Archer Daniels Midland (Decatur, IL) and calcium chloride was from Wright Nutrition (Crowley, LA). Glycerol and carboxymethyl cellulose (CMC) were from Sigma Chemical (St. Louis, MO). Glycerol and calcium chloride were food-grade. Fresh potatoes (Russet), onions (Yellow), carrots (Bolero), and apples (Golden Delicious) were obtained from a local grocery. All other reagents were analytical grade.

Proximate analysis. The proximate analysis of SPI was determined in triplicate by Association of Official Agricultural Chemists (AOAC) methods (moisture, 934.01; fat, 920.39; protein, 988.05; ash, 942.05) (1990).

Preparation of coating solution. Edible coating solutions were prepared as described in the previous paper [Shon and Chin, 2008]. A 5\% (w/v) aqueous solution of SPI was added to glycerol $(2.5 \%, \mathrm{w} / \mathrm{v}), \mathrm{CaCl}_{2}(0.125 \%$, w/v) with and without CMC $(0.25 \%, w / v)$ with constant vortexing, followed by degassing, heat treatment at $90^{\circ} \mathrm{C}$ for $30 \mathrm{~min}$, homogenization, filtration, cooling and final degassing. The solution was stored at $2^{\circ} \mathrm{C}$ before use.

For the coating process, five slices $\left(2.5 \mathrm{~cm}^{3}\right)$ were cut from each of 3 potatoes, 3 carrots, 3 onions, and 3 apples. The samples were randomly assigned for the control and coating treatment. The samples were dipped for $1 \mathrm{~min}$ at room temperature $\left(22 \pm 1^{\circ} \mathrm{C}\right)$ in the coating solutions and drained for 10 $\mathrm{s}$. The samples were then dried under a clean air flow for $2 \mathrm{~min}$ $\left(22 \pm 1^{\circ} \mathrm{C}\right)$ and packed immediately in a polystyrene foam food box and refrigerated at $4^{\circ} \mathrm{C}$ and analyzed for up to 5 day. The control samples were dipped in deionized distilled water (DDW) instead of SPI coating solution and drying was as for the treatments.

Preparation of film-forming solution. Films used for measuring antioxidative capacity were based on SPI, glycerol,
$\mathrm{CaCl}_{2}$, and $\mathrm{CMC}$. Solutions containing 5\% SPI, 2.5\% glycerol, $0.125 \% \mathrm{CaCl}_{2}$, and with or without $0.25 \% \mathrm{CMC}$ were heated at $90^{\circ} \mathrm{C}$ for $30 \mathrm{~min}$ with constant vortexing, followed by cooling at room temperature $\left(22 \pm 1^{\circ} \mathrm{C}\right)$ and adjusting the final solution to $\mathrm{pH}$ 6.5. Films were cast by applying $5 \mathrm{~mL}$ of the solution onto a $8.5 \mathrm{~cm}$ diameter Petri dishes (SPL Life Sciences Co., Pocheon, Korea) and allowed to dry $24 \mathrm{~h}$ at room temperature. Dried films were peeled intact from the casting surface and reconditioned in a desiccator containing a saturated $\mathrm{NaBr}$ solution, ensuring $50 \pm 5 \%$ relative humidity $(\mathrm{RH})$ at room temperature, for $48 \mathrm{hr}$ [Gontard, et al., 1992].

Evaluation of antioxidative activity. Antioxidative capacity of film was evaluated using the modified procedure of the DPPH (2,2-diphenyl-1-picryh) radical scavenging activity, as described by Li et al. [2007].

Measurement of film thickness. Film thickness was determined using a Mitutoyo Digimatic Indicator (Mitutoyo, Tokyo, Japan) at 5 random locations around the film. The average film thickness was in the range of $50 \pm 5 \mu \mathrm{m}$ and depended upon the formulation.

Determination of DPPH radical scavenging activity. Films were cut in pieces of equal thickness $(50 \pm 5 \mu \mathrm{m})$ and mixed with $1.0 \mathrm{~mL}$ of $0.2 \mathrm{mM}$ DPPH solution. After incubating $30 \mathrm{~min}$, the absorbance of the resulting solutions was measured at $517 \mathrm{~nm}$ using an UV-visible spectrophotometer (Shimadzu Co., Kyoto, Japan). The control was conducted in the same manner except that DDW was used instead of sample. The DPPH radical scavenging activity was calculated as follows:

Radical scavenging activity $(\%)=1-[($ Absorbance of sample $)] /$ (Absorbance of control) $] \times 100$

Color measurements. A Minolta 508d spectrophotometer (Hunter Associates Laboratory, Ramsey, NJ), which was standardized using a white blank, was used for color evaluation based on Commission Internationale De I'Eclairage (CIELAB) (1976) color scales, $L^{*}$ (lightness), $a^{*}$ (redness) and $b^{*}$ (yellowness) units. Color measurements were taken at $15 \mathrm{~min}$ intervals up to 120 min due to accelerated browning in fresh-cut fruit and vegetable. Five readings on the upper side of each sample were averaged for color measurement.

Percent moisture loss (PML). The PML was determining after storage of coated and uncoated fruit and vegetables at $4^{\circ} \mathrm{C}$ for up to 5 days as described before [Shon and Haque, 2007a] and expressed as a percentage of the sample initial moisture content (MC). The initial MC of samples was determined and calculated using AOAC standard method (1990) as described earlier [Shon and Haque, 2007a].

$\operatorname{PML}(\%)=[($ initial MC final MC) $/$ initial MC $] \times 100$

Statistical design and analysis. The experiment was 
performed in triplicate and the data were analyzed using a 6 (storage times) $\times 3$ (treatments) factorial design using the general linear model (PROC GLM) procedure of a SAS Statistical Program, version 8.1 (SAS Institute, Cary, NC) for Windows environment (2001). Means were separated using Fisher's protected least significance test $(p<0.05)$.

\section{Results and Discussion}

Since the interactions between treatment and storage time were significant $(p<0.05)$ for all parameters tested, the data were separated out by treatments within the storage time or by storage times within the same treatment.

Proximate analysis. The mean values of SPI of moisture,

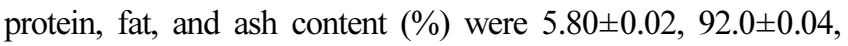
$0.80 \pm 0.02$, and $4.30 \pm 0.02$, respectively.

Antioxidative activity of soy protein films. The antioxidative activity of soy protein films is presented in Fig. 1. The SPI film containing CMC had better antioxidative capacity than that based only on SPI film. The antioxidative capacity of SPI film was $42.3 \%$. When CMC was added to the film formulations, the antioxidative capacity increased to $51.4 \%$ for SPI. Furthermore, the addition of CMC increased the antioxidative capacity of this film by $18.5 \%$ for the SPI formulations. These results indicated a synergistic effect of CMC.

Many factors could account for the antioxidative properties of soy protein films. In addition to cysteine, aromatic amino acids like tyrosine, tryptophan and histidine are potent free radical targets [Elias et al., 2008]. Furthermore, a previous report demonstrated that the antioxidative activity of soy protein in a liposomal system was related to the residual antioxidative phenolic compounds in SPI [Peña-Ramos and Xiong, 2002]. The SPI contain phenolic compounds $(1.5 \mathrm{mg} / \mathrm{g})$, including isoflavonoids that could stabilize free radicals [Peña-Ramos and Xiong, 1984]. Similarly, the addition of a polysaccharide like $\mathrm{CMC}$ can probably also increase the antioxidative activity of these formulations. The CMC was incorporated into coating solution, and the carboxylic groups, which act as a chelating agent under certain conditions, may have caused the antioxidative activity [Sapers, 1993]. Previous reports demonstrated that SPI effectively inhibited lipid oxidation in ground beef [Wu and Brewer, 1994] and in fresh pork patties [McCarthy et al., 2001], and reduced retail storage time related to oxidative degradation of cut Han-woo beef during storage [Shon et al., 2010].

This may be attributed to the effective $\mathrm{O}_{2}$ barrier properties of soy protein films or coatings [Brandenburg et al., 1993]. During the preparation of the coating material, heat treatment resulted in the formation of intermolecular disulfide and hydrophobic bonds and produced Maillard reaction products (MRPs) that may

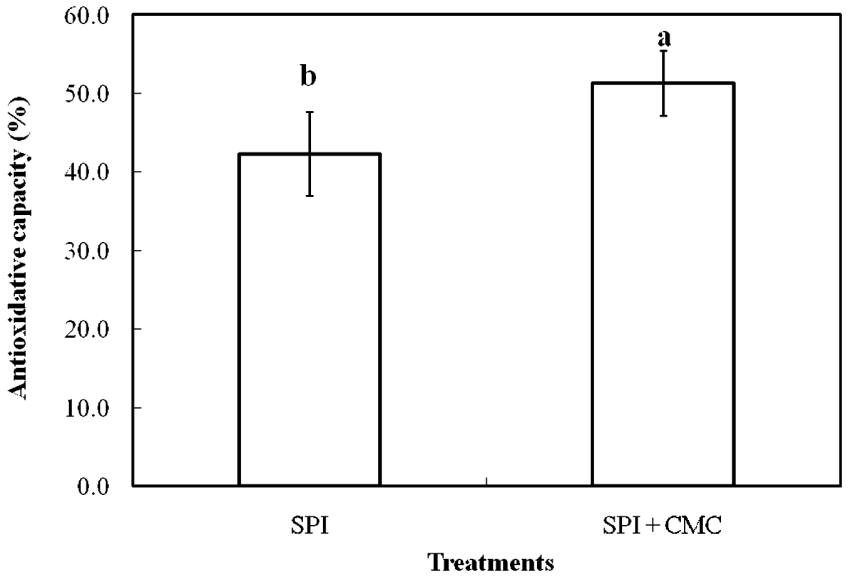

Fig. 1. Antioxidative capacity (\%) for film formations based on soy protein isolate with or without CMC. Each value represents a mean of three replications \pm standard deviations. Dissimilar letters above bars indicate significant difference $(p<0.05)$. SPI=soy protein-coated sample; SPI $+\mathrm{CMC}=\mathrm{SPI}$ with $\mathrm{CMC}$.

possess antioxidant activity [Shon and Haque, 2007a]). The soluble protein and peptide rich protein favors the formation of MRPs, which involves reaction of amino groups of proteins and more readily, with the free amino acids and peptides. Protein hydrolyzates react much more rapidly to yield MRPs that have good free-radical scavenging capability [Elias et al., 2008].

Color measurements. The variation of the lightness parameter $\left(L^{*}\right)$ as a function of time for the control (uncoated) and coated slices is presented in Table 1. For the control apple slices, the $L^{*}$ value decreased significantly $(p<0.05)$ from 87.7, which was the initial reading at $15 \mathrm{~min}$, to 80.2 after $120 \mathrm{~min}$ (Table 1). This reflected a $8.56 \%$ loss of lightness during the experimental period (Fig. 2). Under the same conditions, the loss of $L^{*}$ values of the coated apple slices was much smaller being 4.03 and $3.71 \%$ for SPI coating with and without CMC, respectively (Fig. 2). This showed that the SPI coating was working and significantly the better with and without CMC. The $L^{*}$ value is an important parameter that affects the attractiveness of fruits and vegetables. Reduction of this value results in a pale and "not-fresh" appearance. The $L^{*}$ value of control potato slices significantly decreased during the test period (Table 1). This value had decreased from 81.5 at the initial storage time to 68.5 within $30 \mathrm{~min}$, and by the 120 , which means decrease by $24.0 \%$. The SPI-coated samples fared significantly better (Table 1). It was 7.47 and 6.21 , respectively for SPI with and without CMC. Data indicated that the SPI coatings effectively protected the potato slices from oxygen. The discoloration that occurs in cut apple and potato is mostly due to enzymatic browning catalyzed by PPO [Sapers, 1993].

In cut carrots, both the control and coating slices became paler with time. The onion slices showed no change in lightness value over time in the control (Table 1). After $120 \mathrm{~min}$, the lightness of 
Table 1. Effect of storage on CIELAB color scale values of coated and uncoated fruit and vegetables ${ }^{1)}$

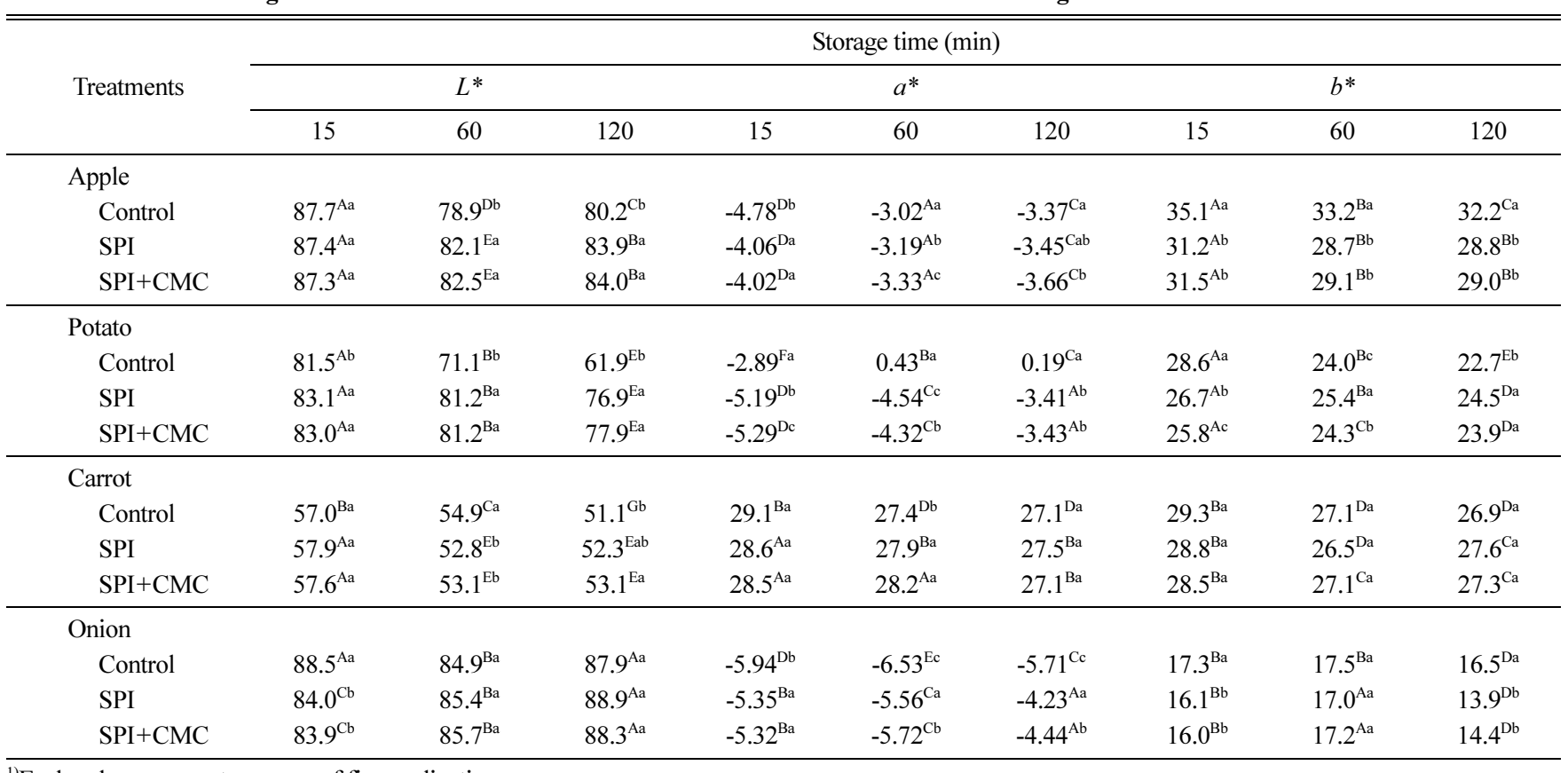

${ }^{1)}$ Each value represents a mean of five replications.

* $\mathrm{ABCDEFG}$ Means within the same row and CIE color scale type with same letters are not significantly different $(p<0.05)$.

${ }^{*}$ abcde Means within the same column and vegetable or fruit with same letters are not significantly different $(p<0.05)$.

Control=uncoated sample; $\mathrm{SPI}=$ soy protein coated sample; $\mathrm{SPI}+\mathrm{CMC}=\mathrm{SPI}$ with $\mathrm{CMC}$.

the control onion slices was 87.9 and similar values (88.9 and 88.3) were noted for the SPI-coated slices. In the coated onion samples, the lightness increased by 5.79 and $5.24 \%$ for SPI coatings with and without $\mathrm{CMC}$, respectively (Fig. 2). This implies that PPO-mediated degradation of sheen and lightness does not take place in the onion. A previous report indicated that onion extract inhibited the browning of PPO in pear [Fujii and Hosoda, 2005]. The active substances of onion juice extract were shown to inhibit PPO in apple. Monosulfides such as allyl propyl monosulfide of onions or Liliaceae plants are used to prevent of Maillard reaction and browning of food [Hosoda et al., 2005]. A previous report indicated that edible coating formulations containing vegetable oils, cellulose gums, emulsifiers, surfactants, and fatty acids reduced enzymatic browning on sliced mushrooms [Nisperos-Carriedo et al., 1991]. Data showed that SPI-based coatings were effective in controlling oxidative browning of sliced fruit and vegetables even after $120 \mathrm{~min}$ (Table 1).

Data show increase in the reddishness ( $a^{*}$ value) of apple slices implying browning with time and this was significantly reduced by the treatments (Table 1). On a percent basis, the increase in browning was 29.5, 15.0 and $8.96 \%$, respectively, for control and SPI with and without CMC (Fig. 2). This meant that the SPI-coated apple slices, regardless of CMC, were greener, and therefore fresher looking, than the control apple slices $(p<0.05)$. In potato, the control potato slices became redder than the SPI-coated potato slices as seen by their higher $(p<0.05) a^{*}$ values (Table 1). This indicated that the SPI-coated potato slices were greener than the control potato slices $(p<0.05)$ (Fig. 2). The treatment effect of SPI in reducing browning was significant. It caused almost a three fold reduction compared with the control (34.3 and 35.2 compared with 106.6\%) (Fig. 2). For carrots, the control and SPI-coated slices showed no significant change in the $a^{*}$ values during the experimental period of $120 \mathrm{~min}$ (Table 1). The control onion samples showed no significant change in $a^{*}$ values after $120 \mathrm{~min}$ and the SPIcoated samples showed a small but significant increase in redness (Fig. 2). This implied that cut onion is not susceptible to PPO-mediated off-color as the other items were tested. Our recent related work has shown SPI coating was effective in reducing oxidative degradation of lipids and in maintaining the color of cut raw Han-Woo beef during refrigerated storage under aerobic packaging [Shon et al., 2010].

There was little variation in the $b^{*}$ values in both the coated and control apple slices (Table 1). The potato slices showed a significant treatment effect in the decrease of the $b^{*}$ values, which the slices got a bluish hue with time, indicating oxidative degradation. The control showed a reduction of the natural yellowish hue by $20.5 \%$ in $120 \mathrm{~min}$ in contrast to 8.26 and 7.14\% for SPI with and without CMC, respectively (Fig. 2). This indicates a synergistic effect of CMC. There was little variation of the $b^{*}$ value between coated and uncoated carrot and onion slices (Table 1).

A previous report indicated that the addition of soy protein 


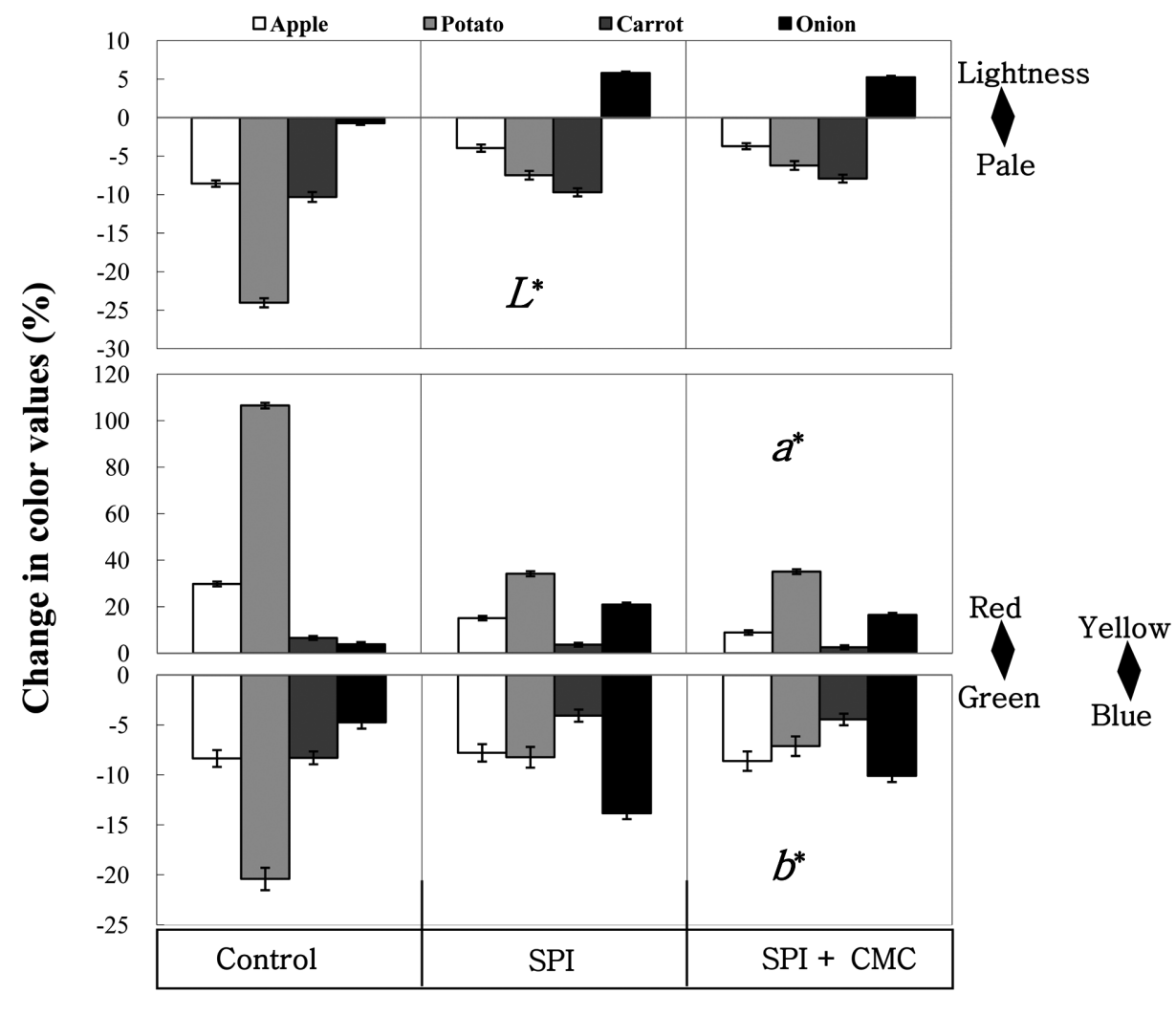

Treatments

Fig. 2. Changes in color values of cut fruit and vegetables with soy protein-based edible coating after 120 min storage at $4^{\circ} \mathrm{C}$. Each value represents a mean of five replications \pm standard deviations. Control=uncoated sample; SPI=soy protein-coated sample; SPI $+\mathrm{CMC}=\mathrm{SPI}$ with $\mathrm{CMC}$.

improved antioxidative activity in a liposomal system [PeñaRamos and Xiong, 2002]. Protein coatings probably delay browning by preventing the oxidative process. An important factor implied in the inhibition of the oxidative browning is that the coating by protein solution represents an efficient barrier to oxygen (decreased oxygen penetration). Additional effects could be related to the presence of other components in the film or coating formulation. For instance $\mathrm{CMC}$, as carbohydrate, can exert a nonspecific oxidative species scavenging activity [Wehmeier and Mooradian, 1994]. Another possible beneficial effect can be related to the carboxylic groups of $\mathrm{CMC}$, which in certain conditions as a chelating agent, can interact with the copper binding site for the oxygen and decrease PPO activity [Sapers, 1993]. Calcium chloride, a divalent salt, is often incorporated into the coating solution to improve the texture and color of food products. Adding calcium salts to soy-protein coatings may control darkening of fruits and vegetables [Park et al., 2001]. A previous report showed that alginate-based coating solution, a carbohydrate having a carboxylic group, was effective in maintaining the better appearance and color of the mushroom for a long period [Hershko and Nussinovitch, 1998]. Various chemicals including sulfite, citric acid, ascorbic acid derivatives, cinnamate, benzoate, and cyclodextrins are used to reduce browning [Sapers, 1993]. Data suggest that SPI-based edible coatings, regardless of $\mathrm{CMC}$, were successful in delaying oxidative browning in sliced fruit and vegetables.

Moisture barrier property. The storage time was found to have a significant effect on $\mathrm{MC}$, while the interaction of treatment and storage time was also significant $(p<0.05)$ (Fig. $3)$. The MC of both the control and SPI-coated samples, regardless of $\mathrm{CMC}$, decreased significantly all test items, during the experimental period of 5 days $(p<0.05)$ (Fig. 3). However, the rate of decrease in $\mathrm{MC}$ was reduced by SPI coating with and without CMC.

The PML varied significantly among the test items and between treatment and control (Fig. 4). The PML for all test samples significantly increased during storage time. The SPI coating was significantly successful in reducing moisture loss in apple slices. Its effectiveness as a moisture barrier was observed after 1 day of storage time, its PML was 32.7 and 26.3 in contrast to $51.5 \%$ for the control; a reduction by 21.3 and $36.9 \%$ for SPI coating with and without CMC, respectively. Potato slices also showed a reduction of moisture loss over control by 29.6 and $41.3 \%$ for SPI coating with and without CMC, respectively. The reduction of moisture loss was also observed in cut carrots where SPI coatings reduced moisture loss by 27.9 


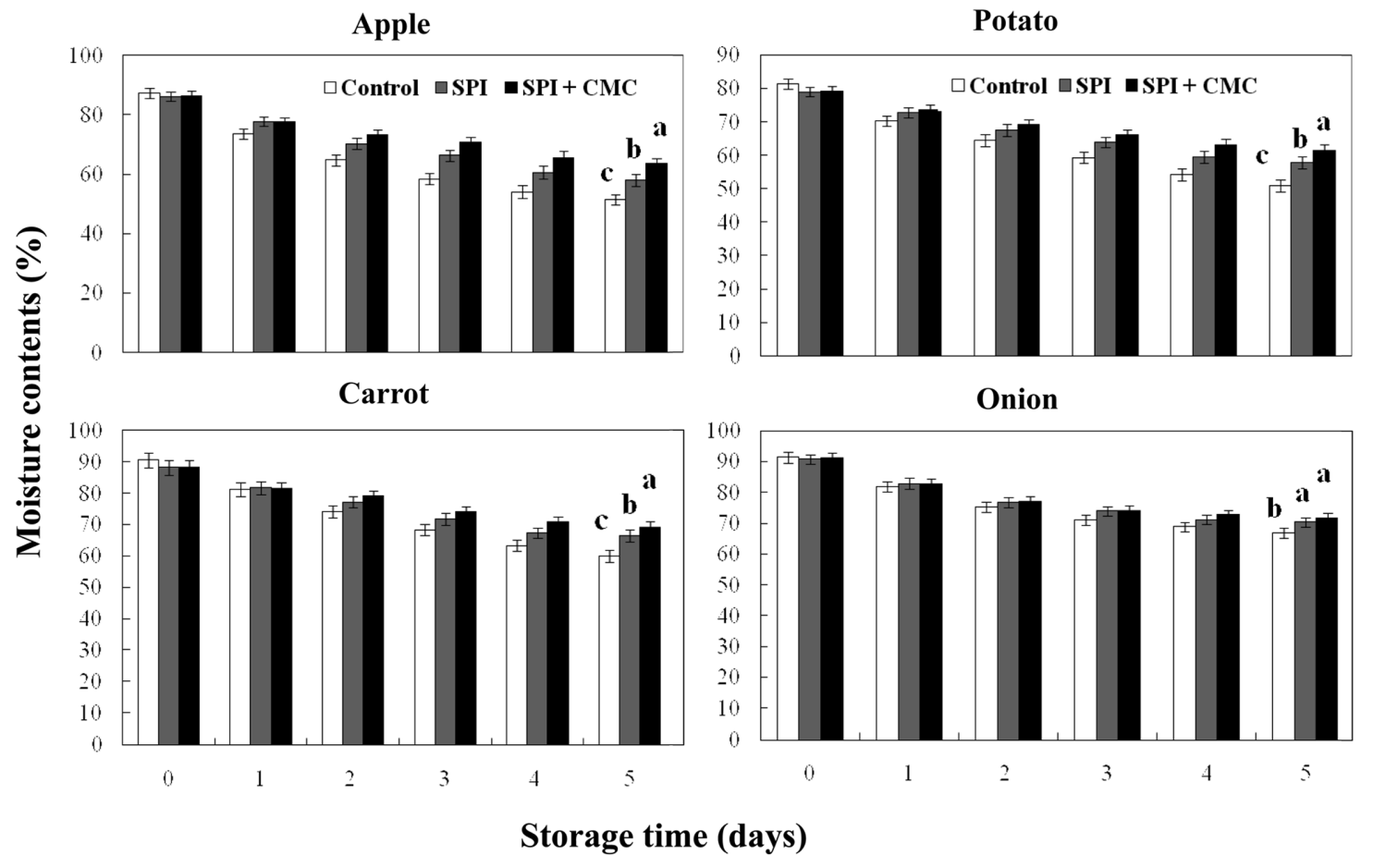

Fig. 3. Moisture contents of cut fruit and vegetables with soy protein-based edible coating during storage at $4^{\circ} \mathrm{C}$ for 5 day. Dissimilar letters above bars indicate significant difference $(p<0.05)$. Control=uncoated pork; SPI=soy protein-coated pork; SPI + CMC=SPI with CMC.

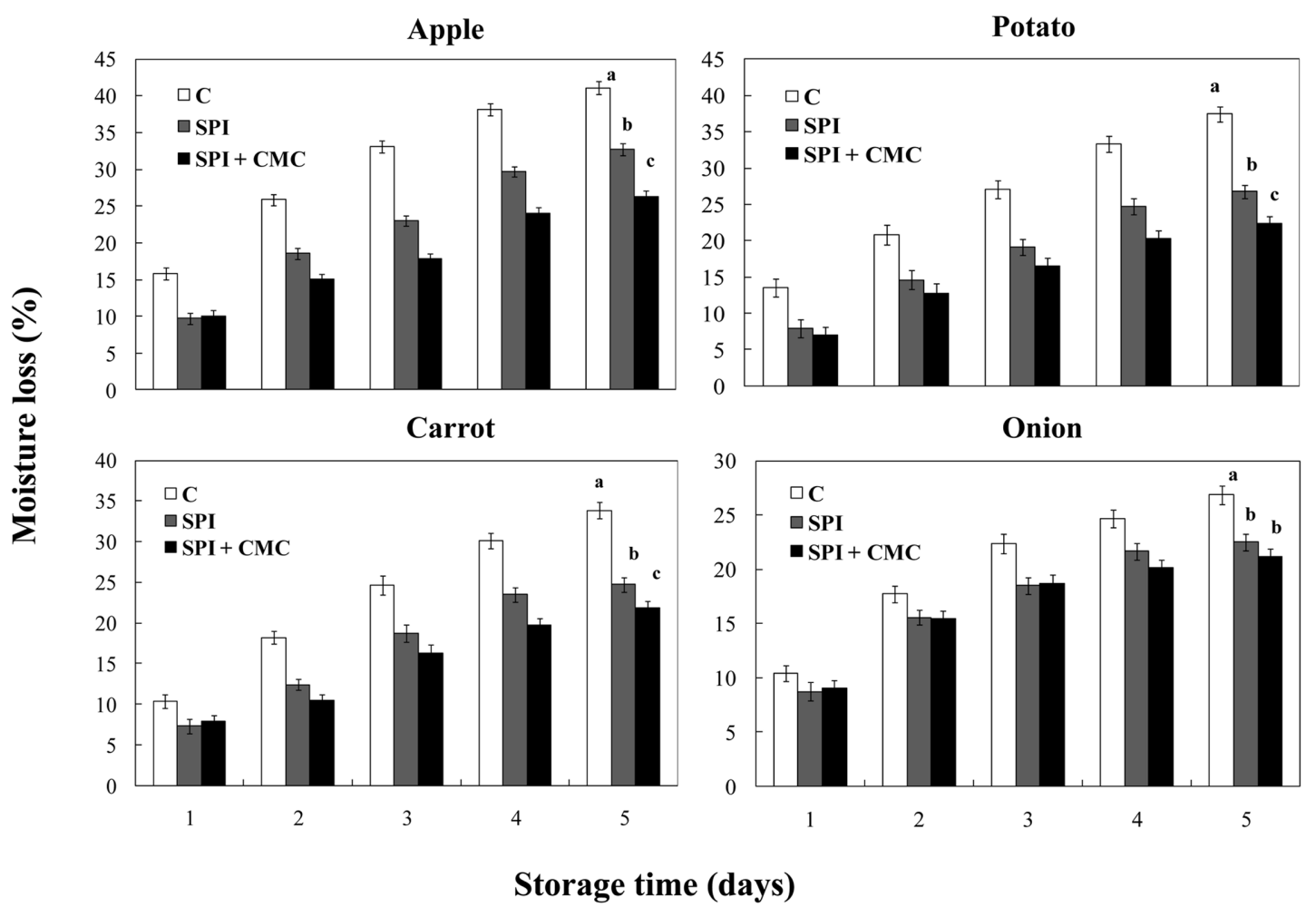

Fig. 4. Percent moisture loss of cut fruit and vegetables with soy protein-based edible coating during storage at $4^{\circ} \mathrm{C}$ for 5 day. Dissimilar letters above bars indicate significant difference $(p<0.05)$. Control=uncoated pork; SPI=soy protein-coated pork; SPI $+\mathrm{CMC}=\mathrm{SPI}$ with $\mathrm{CMC}$.

and $36.6 \%$ over the control by the end of the 5 day storage time. In onions, the little variation in the PML except for a small but significant difference between the control and SPI-coated slices at the end of the 5 days (Fig. 4). The onion slices had the least moisture loss, but there was benefit of coatings with SPI. The SPI coatings reduced moisture loss by 17.2 and $22.2 \%$ over the 
control by the end of the 5 day storage period. The SPI-coated samples had the less amount of moisture loss. A previous report indicated that soy protein coating effectively reduced the moisture loss in precooked beef patties [Wu et al., 2000]. Mixing of CMC with the SPI in the coating mixture resulted in significant improvement of the PML value by 20.5, 17.4 and $12.8 \%$ for apple, potato and carrot, respectively (Fig. 4). This indicates a synergistic effect of CMC. However, there was a small improvement (7.01\%) in the PML value of the onion slices though the difference was not significant. Data show that excellent moisture barrier property of SPI by itself. During the preparation of the coating material, the mixture is homogenized for $2 \mathrm{~min}$, resulting in the formation of oil-in-water emulsion. Therefore, good emulsification properties of proteins correlated linearly with surface hydrophobicity [Shon and Haque, 2007b]. It is conceivable that the SPI coating was so effective as a moisture barrier because of its hydrophobic nature [Shon and Haque, 2007b]. The SPI films formulated with calcium salts have potential as moisture barriers in cut raw Han-Woo beef due to the hydrophobicity of protein [Shon et al., 2010].

\section{References}

Brandenburg AH, Weller CL, and Testin RF (1993) Edible films and coatings from soy protein. J Food Sci 58, 1086-1089.

Elias RJ, Sarah SK, and Decker EA (2008) Antioxidant activity of proteins and peptides. Crit Rev Food Sci Nutr 48, 430-431.

Fujii H and Hosoda H (2005) Control effect of onion juice extraction for browning of vegetable and fruit. 1. Kenkyu Hokoku-KagawaKen Sangyo Gijutsu Senta 5, 99-100.

Fujita S, Tono T, and Kawahara H (1991) Purification and properties of polyphenol oxidase in head lettuce (Lactuca sativa). J Sci Food Agric 55, 643-651.

Gontard N, Guilbert S, and CuQ JL (1992) Edible Wheat gluten films: influence of the main process variables on film properties using response surface methodology. J Food Sci 57, 190-199.

Haque ZU, Shon J, and Williams B (2009) Efficacy of sour whey as a shelf-life enhancer: Use in antioxidative edible coatings of beef steak. J Food Quality 30, 581-593.

Hershko V and Nussinovitch A (1998) Relationships between hydrocolloid coating and mushroom structure. J Agric Food Chem 46, 2988-2997.

Hosoda H, Inoue E, Iwahashi Y, Sakaue K, Tade M, and Nagata T (2005) Inhibitory effect of sulfide on browning of apple slice. Nippon Shokuhin Kagaku Kogaku Kaishi 52, 120-124.

Kester JJ and Fennema O (1986) Edible lms and coatings: A review. Food Technol 40, 47-59.

Le Tien C, Vachon C, Mateescu MA, and Lacroix M (2001) Milk protein coatings prevent oxidative browning of apples and potatoes. J Food Sci 66, 512-516.

Li B, Chen F, Wang X, Ji B, and Wu Y (2007) Isolation and identification of antioxidative peptides from porcine collagen hydrolysate by consecutive chromatography and electrospray ionization-mass spectrometry. Food Chem 102, 1135-1143.

Liu G, Xiong YL, and Butterfield DA (2000) Chemical, physical, and gel forming properties of oxidized myofibrils and whey- and soyprotein isolate. J Food Sci 65, 811-818.

McCarthy TL, Kerry JP, Kerry JF, Lynch PB, and Buckley DJ (2001) Assessment of the antioxidant potential of natural food and plant extracts in fresh and previously frozen pork patties. Meat Sci 57, 177-184.

McHugh TH and Senesi E (2000) Apple wraps: A novel method to improve the quality and extend the shelf life of fresh-cut apples. $J$ Food Sci 65, 480-485.

Nisperos-Carriedo MO, Baldwin EA, and Shaw PE (1991) Development of an edible coating for extending postharvest life of selected fruits and vegetables. Proc Florida State Hort Soc 104, 122-125.

Park SK, Rhee CO, Bae DH, and Hettiarachchy NS (2001) Mechanical properties and water-vapor permeability of soyprotein films affected by calcium salts and glucono-delta-lactone. J Agric Food Chem 49, 2308-2312.

Peña-Ramos EA and Xiong YL (2002) Antioxidant activity of soy protein hydrolysates in a liposomal system. J Food Sci 67, 29522956.

Sapers GM (1993) Browning of foods: Control by sulfites, antioxidants and other means. Food Technol 47, 75-84.

Shon J and Chin KB (2008) Effect of whey protein coating on quality attributes of low-fat, aerobically packaged sausage during refrigerated storage. J Food Sci 73, C469-473.

Shon J and Haque ZU (2007a) Efficacy of sour whey as a shelf-life enhancer: Use in antioxidative edible coatings of cut vegetables and fruit. J Food Quality 30, 581-593.

Shon $\mathrm{J}$ and Haque ZU (2007b) Functional attributes of native and thermized sour and sweet whey. Int J Dairy Technol 60, 135-142.

Shon J, Eo JH, and Eun JB (2010) Effect of soy protein isolate coating on quality attributes of cut raw Han-Woo (Korean cow) beef, aerobically packaged and held refrigerated. J Food Quality 33, 4260.

Wehmeier KR and Mooradian AD (1994) Autoxidative and antioxidative potential of simple carbohydrates. Free Radic Biol Med 17, 83-86.

Were L, Hettiarachchy NS, and Coleman M (1999) Properties of cysteine-added soy protein-wheat gluten films. J Food Sci 64, 514-518.

Wu SY and Brewer MS (1994) Soy protein isolate antioxidant effect on lipid peroxidation of ground beef and microsomal lipids. $J$ Food Sci 59, 702-706.

Wu Y, Rhim JW, Weller CL, Hamouz FA, Cuppett S, and Schnepf M (2000) Moisture loss and lipid oxidation for precooked beef patties stored in edible coatings and films. J Food Sci 65, 300-304.

Zhang Q, Tan S, McKay A, and Yan G (2005) Carrot browning on simulated market shelf and during cold storage. J Sci Food Agr $\mathbf{8 5}$, $16-20$. 